水文・水資源学会誌

J. Japan Soc. Hydrol \& Water Resour.

\begin{tabular}{ll} 
Vol. 6. No. 1 (1993) & PP. 31-35 \\
\hline
\end{tabular}

\title{
乾燥裸地面からの蒸発に及ぼす温度勾配の影響
}

\author{
小林哲夫*
}

\section{Effects of thermal gradients on the evaporation from a dry soil surface}

\author{
Tetsuo KOBAYASHI
}

The role of thermal gradients played in the evaporation process from bare soil after the dry surface layer (DSL) forms is discussed. Water moves only in the vapor phase within the DSL. There exist two mechanisms by which water vapor transfer is influenced by temperature gradients ; that is, thermal diffusion and thermal dependence of saturation vapor density. The former can be ignored within the DSL, but the latter cannot be neglected when the daily amount of evaporation is much smaller than $0.1 \mathrm{~mm} \mathrm{day}^{-1}$. On the other hand, in the thin air layer next to the ground surface, very large temperature gradients can exist during the day, when the water vapor is forced upward through the layer by thermal diffusion. Consequently, even if water vapor inversion occurs in the thin air layer, water vapor can move upward through the layer against the gradient.

Key words: bare-soil evaporation, temperature gradient, thermal diffusion, DSL

水分移動が水蒸気体でのみ行われる乾燥表層 (DSL) が形成された後の蒸発過程における温度勾配の役割が考察される.温度勾 配が水蒸気輸送に影響を及ぼす機䊗は 2 種類ある。すなわち熱掂散と飽和水蒸気密度の温度依存性である.DSL内においては，前 者は無視できるが，後者は，日蒸発量が0.1mmを下回るようになると，無視できない. 一方，地表面直上の空気薄層内では，日中， 極めて大きな温度勾配が存在しうる. そのとき接地薄気層内の水蒸気は熱拡散によって強力に上方へ押しやられる.したがって, 接地薄気層内で湿度逆転が生じている場合でも，水蒸気は勾配に逆らって同層を通過し，上方八移動することができる。

キーワード: 裸地面蒸発, 温度勾配, 熱拡散, DSL

\section{I 、はじめに}

地表面の乾燥が進み，水分移動が水蒸気体での み行われる乾燥表層（DSL）が形成されると，日中， 地表面温度は著しく上昇する. 砂丘地や砂漠などで は，このような状態が日常的に現れる。

水蒸気体での水分移動は温度勾配の影響を強く受 ける，したがって，DSLが形成された段階における 蒸発過程は, 温度勾配の役割を考慮せずに正しく理 解することはできない。

本報では，乾燥裸地面からの蒸発過程を単純にモ デル化し, 温度勾配の役割について総括的に論じる. また, 乾燥裸地面からの蒸発速度測定法の原理とそ
の適用に対して温度勾配が及ぽす影響を考察する。

\section{Fickの法則と熱拡散}

水蒸気の拡散フラックスを表す基礎式としては， 一般にはFickの法則が用いられる，鉛直方向 $(z$ 方 向, 图一-1）の1次元現象を考えることにすれば（以 後, 同様), 次式のように表すことができる.

$$
-j_{v}=D\left(\partial \rho_{v} / \partial z\right)
$$

ここで $j_{v}$ は水蒸気の鉛直上向き拡散フラックス, $\rho_{v}$ は水蒸気密度, $D$ は現象論的係数である.これは経験 的に得られた法則であり，特に単純な条件の下にあ る場合を除いて, 理論的根拠を持たない (Truesdell, 1962). 
Philip and de Vries (1957)は，(1)式に基づいて温 度勾配下に扔ける有孔性媒体内の水蒸気移動を定式 化した。い, $z$ 方向に温度 Tが変化しているとすれ ば, (1)式は次のように書ける。

$$
-j_{v}=D\left\{\left(\partial \rho_{v} / \partial z\right)_{T}+\left(\partial \rho_{v} / \partial T\right) \cdot\right.
$$$$
(\partial T / \partial z)\}
$$

ここで添字 ${ }_{T}$ は温度一定の条件を意味する. 右辺第 2 項が温度勾配に依存するフラックスを表す。（ $\partial \rho_{v} /$ $\partial T$ ) は水蒸気密度の温度依存性を表しており, 自由 空間内でも気体の膨張の影響を反映するが，実際に は水蒸気が液体水と共存している有孔性媒体の間げ き内においてのみ意味を持つ (V. 節参照)。すなわ ち, 飽和水蒸気密度 (厳密には平衡水蒸気密度)の温度 依存性に基づくフラックスを表してる。しかし，水 蒸気移動の駆動力はあくまでも水蒸気密度の勾配で ある。

熱拡散は温度勾配そのものが駆動力となる輸送現 象である (de Groot and Mazur, 1984). Bearman and Kirkwood (1958) は多成分系内の輸送方程式を統計 力学に基づいて誘導した。位相空間内での分布関数 を平衡項と捸動項に分離し, 後者を温度勾配, 拡散 速度および変形速度の線形関数によって表現するこ とにより, 準定常状態での運動方程式を得た. 各成 分に作用する平均的な力は化学ポテンシャルの勾配 を含む熱力学項, 温度勾配に比例する項, 局所的質 量中心に相対的な拡散速度に比例する項, おるび変 形速度を含む粘性項に分離される.Bearman (1959) は, 上記準定常運動方程式に基づき, 輸送現象を記 述する慣性項と粘性項をも含む現象論的方程式を得 た. 彼の結果を本研究の場合に適用すれば次式とな る.

$$
\begin{aligned}
-j_{v}= & L_{v v}\left(F_{v}-\left(M_{v} / M_{d}\right) F_{d}\right) \\
& +L_{v q}(\partial \ln T / \partial z)
\end{aligned}
$$

ここで $L_{v v}$ と $L_{v q}$ は現象論的係数, $F$ は慣性項と粘性 項を含む平均化された作用力, $M$ は分子量, また添 字 $v$ とdは水蒸気と乾燥空気を意味する. 右辺第 2 項 が熱拡散を表す項である.

慣性項と粘性項, および重力ポテンシャルは無視 できるものとし, 水蒸気は希薄であり, 理想気体近 似ができるものとすれば，(3)式は次のように書くこ とができる.

$$
\begin{aligned}
-j_{v}= & L_{v v}\left(R_{w} T / \rho_{v}\right)\left(\partial \rho_{v} / \partial z\right)_{T} \\
& +L_{v q}(1 / T)(\partial T / \partial z)
\end{aligned}
$$

ここで $R_{w}$ は水蒸気の気体定数である.(4)式では(3)式 の $F$ として熱力学項のみを考慮していることになる。
(4)式はまた別の方法で誘導することも可能である (小林ら，1985)。 また，係数 $L_{v q}$ は正になることが確 かめられている (Cary, 1963).

(2)式と(4)式の右辺第 1 項は等温拡散を意味し, 物 理的に同じ内容を表すが, それぞれの第 2 項は全く 異なる現象を表すことに注意しなければならない。 (2)式の第 2 項は温度勾配が水蒸気密度の勾配をもた らすような状況でのみ実際的な意味を持つが，(4)式 の第 2 項が表す現象は一般的な状況の下で存在する 非平衡現象の一種である。

\section{III. モ デル}

地表面温度が極めて上帠する日中の乾燥裸地面か らの蒸発過程を模式化して図一 1 に示す. DSL内お よび地表面では, 水分は土粒子表面に付着 (吸着)し ており, 水分輸送は分子拡散 (点影部) と渦拡散に よって行われる.間げき内の水蒸気密度は同一染さ における土粒子表面の付着水と熱力学的平衡状態に ある (Milly，1982)。液体水から水蒸気への気化は DSLより更に下層で行われる。

地表面直上の空気薄層 (以後, 接地薄気層) 内でも 分子拡散による水蒸気輸送が行われる．層厚 $b$ は熱 的・学的条件によって変化するものと思われる. 仮に対流が発生しないための熱的条件（レイリー数 $\left.R_{a}<10^{3}\right)$ を適用してみると, $10^{-3} \mathrm{~m} よ り$ 薄いという結 果が得られる。これが一つの目安と考える。

間げきが地面に開口する部分では，土粒子径や地 上風速にも依存するが，渦拡散の支配する領域が侵 入する. Ishihara et al. (1992)は10-2mのオーダー
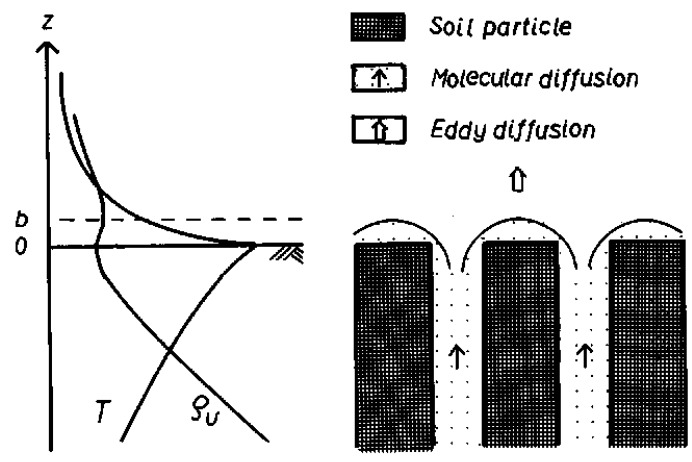

图一1（右)竞燥操地面を形成する土粒子とそれを取り

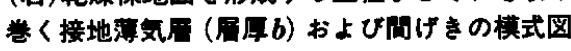
点影部は分子抬散が支配する領域を示す (左) 地表面付近の温度 $(T)$ と水蒸気密度 $\left(\rho_{v}\right)$ の平均的プロフィールの模式図 
の深さまで侵入しうるとしているが，筆者らは無視



(Kobayashi et al., 1989).いずれにしても，地表面 近傍の温度と水蒸気密度の分布の微細構造は複雑で あるが，本報では，図一 1 に模式的に示すような, 平均的なプロフィールを対象にして考察を進める. したがって温度勾配の影響と言っても, 平均化され た影響であることは言うまでもない.

\section{N. 熱拡散の評価}

1 次元水蒸気輸送の基礎式(4)の熱拡散を表す右辺 第 2 項と等温拡散を表す第 1 項の比を $\gamma$ とする.す なわち

$$
\begin{aligned}
\gamma= & L_{v q}(1 / T)(\partial T / \partial z) / \\
& L_{v v}\left(R_{w} T / \rho_{v}\right)\left(\partial \rho_{v} / \partial z\right)_{T} \\
= & s \cdot \rho_{v} \cdot(\partial T / \partial z) /\left(\partial \rho_{v} / \partial z\right)_{T}
\end{aligned}
$$

ここで $s \equiv L_{v q} / L_{v v} R_{w} T^{2}$ はSoret係数である。一般に， 混合気体中でも混合液体中でも, $|s|=10^{-5} \sim 10^{-3}$ K-1であることが実験的に確かめられている（de Groot and Mazur, 1984).

\section{DSL内上部}

DSL内上部では $|\partial \mathrm{T} / \partial z| \approx 10^{3} \mathrm{~K} \mathrm{~m}^{-1}$ (Kobayashi et al., 1991), $\rho_{v} \approx\left(10^{-3} \sim 10^{-2}\right) \mathrm{kg} \mathrm{m} \mathrm{m}^{-3}$ であるか ら, (5)式より次の関係を得る.

$$
|\gamma| \approx\left(10^{-5} \sim 10^{-2}\right) /\left|\left(\partial \rho_{v} / \partial z\right)_{T}\right|
$$

上式は $\left|\left(\partial \rho_{v} / \partial z\right)_{T}\right| \lesssim 10^{-2} \mathrm{~kg} \mathrm{~m}^{-4}$ になると熱拡 散の影響が無視できなくなる可能性のあることを示 している.これは日蒸発量に換算すれば0.01m $\mathrm{day}^{-1}$ よりささ場合に相当するので, 現実の問題 としては，熱拡散の影響は無視してょいと思われる。

\section{2. 接地薄気層内}

接地薄気層内の温度勾配の測定は難しいが, 次の ように推定できる. 地表面から大気中への顕熱伝達 量を $H$, 地中への熱伝達量を $G$ とすれば, 日中, 乾燥 裸地面では $H \approx(1 \sim 10) G$ となる. また, 地表面の 熱源は土粒子表面であるから, 接地薄気層内の熱伝 導率 $\lambda_{a}$ とDSL内の熱伝導率 $\lambda_{d}$ の間には $\lambda_{a} \approx 10^{-1} \lambda_{d}$ の関係がある. したがって, 接地薄気層内の温度勾 配の絶対値はDSL内上部のそれの10〜102倍となり, $|\partial T / \partial z| \approx\left(10^{4} \sim 10^{5}\right) \mathrm{K} \mathrm{m}^{-1}$ と推定される.

水蒸気密度はDSL内上部とほ注等しく, $\rho_{v} \approx\left(10^{-3}\right.$ $\left.\sim 10^{-2}\right) \mathrm{kg} \mathrm{m}^{-3}$ であるから（5)式から次の関係を得
る.

$$
|\gamma| \approx\left(10^{-4} \sim 1\right) /\left|\left(\partial \rho_{v} / \partial z\right)_{T}\right|
$$

上式は $\left|\left(\partial \rho_{v} / \partial z\right)_{T}\right| \approx 1 \mathrm{~kg} \mathrm{~m}^{-4}$ というような極め て大きな水蒸気密度勾配に拮抗する熱拡散の存在が ありうること, $10^{-4} \sim 10^{-2} \mathrm{~kg} \mathrm{~m}^{-4}$ 程度の水蒸気密度 勾配に逆らって水蒸気が運ばれると考えることは決 して不合理でないことを示唆する。

接地薄気層より上の接地大気層 (以後, 接地層) 内 では, 水蒸気は渦拡散によって上方へ運ばれる，接 地層内の水蒸気輸送能力が相対的に小さい場合は, 接地薄気層内で湿度逆転が生じる (Kobayashi et $a l$. 投稿中). すなわち, 高度と共に水蒸気密度は増 す (图一1)。このような条件の下では, 蒸発速度は 接地層内の水蒸気の状態には依存しない, 地表面が 乾燥すると蒸発速度は地中の条件によってのみ決ま るようになると言われるが (Gardner and Hillel, 1962; kondo et al., 1992), その理由の一つとして地 表面直上に発達する大きな温度勾配をあげることが できる.

\section{V. 水蒸気密度の温度依存性の評価}

\section{DSL内}

DSL内では熱拡散は無視してよいので, 水蒸気輸 送の基礎式として(2)式を用いることができる．温度 勾配の影響を表す右辺第 2 項の第 1 項に対する比を $\gamma$ 'とすれば, 次式を得る.

$$
\gamma^{\prime}=\left(\partial \rho_{v} / \partial T\right)(\partial T / \partial z) /\left(\partial \rho_{v} / \partial z\right)_{T}
$$

DSL内上部の条件 $(p F \approx 6, T<340 \mathrm{~K})$ においては (小林・宮川, 1991)，

$$
\begin{aligned}
& \left(\partial \rho_{v} / \partial T\right) / \rho_{v} \approx\left(d \rho_{s} / d T\right) / \rho_{s} \\
& \approx 5 \times 10^{-2} \mathrm{~K}^{-1}
\end{aligned}
$$

となる (Nakano and Miyazaki, 1979). ただし $\rho_{s} は$ 飽和水蒸気密度である.したがって, たとえば $|\partial T / \partial z|=5 \times 10^{2} \mathrm{~K} \mathrm{~m}^{-1}, \rho_{v}=5 \times 10^{-3} \mathrm{~kg} \mathrm{~m}^{-3}$ とすれば, 次の関係を得る。

$$
\left|\gamma^{\prime}\right| \approx 10^{-1} /\left|\left(\partial \rho_{v} / \partial z\right)_{T}\right|
$$

基礎式(2), すなわち(1)式は経験式であり, 理論式 ではないので, $\gamma$ 'の值を厳密に評価してもあまり意 味はないと思われる. しかし, 上記の例の場合, $\left|\left(\partial \rho_{v} / \partial z\right)_{T}\right|<10^{-1} \mathrm{~kg} \mathrm{~m}^{-4}$ では温度勾配の影響 が無視できなくなる可能性を示していると考えられ る.これは熱拡散の影響の判定基準よりオーダーが 1 以上大きい（(6)式参照). 


\section{2. 接地薄気層内}

接地薄気層内では水蒸気の生成・消滅はないので, 気体の膨張の影響だけを評価すればよい。理想気体 モデルを用いれば

$$
\left|\left(\partial \rho_{v} / \partial T\right) / \rho_{v}\right|=1 / T \approx 3 \times 10^{-3} \mathrm{~K}^{-1}
$$

となり, 飽和水蒸気密度の温度依存性の項よりオー ダーが1小さいことがわかる．したがってDSL内で はこの項を無視することができた。しかし，接地薄 気層内の温度勾配はDSL内ょりもオーダーが 1 〜 2 大きいので,

$$
\left|\gamma^{\prime}\right| \approx\left(10^{-1} \sim 1\right) /\left|\left(\partial \rho_{v} / \partial z\right)_{T}\right|
$$
となる。

ここで, 再び基礎式(2)の有効性に立ち返る必要が ある. $10^{3} \sim 10^{4} \mathrm{~K} \mathrm{~m}^{-1}$ のような極めて大きな温度勾 配が存在する条件の下では，基礎式(2)，すなわち(1) 式が成立するという保証はないと考えられる。(10)式 は, 熱拡散の影響の判定基準(7)式と矛盾はしないよ うに見えるが，符号は逆であり，(2)式の第 2 項が表 すフラックスは低温部から高温部へ向かうことにな る.これは $L_{v q}>0$ となる実験事実に反する.

\section{V. 蒸発速度測定法}

\section{1 . 原理上の問面点}

湿潤地での蒸発速度測定法を乾燥裸地面からの蒸 発速度測定に適用する場合には, いくつかの原理上 の問題がある。まず, 地表面の湿度と接地層内の湿 度の差は，一般には蒸発速度に比例しない。地上の 湿度のプロフィールは, 温度勾配の存在によって, 普通は単調関数では表現できないと考えられるから である(图一1)。これは従来用いられているバルク 法などが乾燥裸地面からの蒸発速度測定法としては 適当でないことを意味する。

また, 乾燥裸地面からの蒸発速度は地中の条件に よってのみ決まる傾向が強いだけでなく, 地表面直 上の大きな温度勾配は接地層内の湿度状態が地表面 へ伝わることを妨げるので, 移流現象がなかなか解 消されない.したがって, 移流現象がなく、フラッ クスが一定の気層が存在することを前提とした原理 に基づく測定方法, たとえば渦相関法や傾度法など は適用が難しいことになる。

最近, 日中の砂漠の接地層内で下向きの水蒸気ス ラックスが観測された (Wang and Mitsuta, 1990 ： 原䓢ら,1992).測定は渦相関法やボーエン比法によっ て行われたが, 残念ながら, 移流現象が無視できる 状況下にあったかどうかは確認されていない.

\section{2．DSL法と温度勾眍の関係}

DSL法はDSL内の水分上昇フラックスを層内の 含水量と地温プロフィールから求め, 蒸発速度を推 定する方法である (小林・宮川，1991)，本法には前項 で指摘したような原理上の問題はないが, 温度勾配 が層内の水分上舁フラックスと蒸発速度の一致を保 証する反面, 精度上の制約をもたらす。

前節V.でみたように, DSL内では $\left|\left(\partial \rho_{v} / \partial z\right)_{T}\right|$ $\leq 10^{-1} \mathrm{~kg} \mathrm{~m}^{-4}$ になると温度勾配の影響が無視でき なくなる.これは日蒸発量に換算すると0.1 $\mathrm{mm} \mathrm{day}^{-1}$ より小さい場合に相当し，DSL法の精度の限界を示 唆している.

DSL内の水分上昇フラックスと蒸発速度が一致 するためには，地表面直上の水分を上方へ運ぶ能力 がDSL内の水分上昇フラックスより大きくなけれ ばならない，接地薄気層内に大きな温度勾配が存在 する場合は, 層内の水蒸気は熱拡散によって強力に 上方へ押しやられるので, 地表面から上昇する水蒸 気は問題なく同層上部まで運ばれる，接地層内の水 蒸気輸送能力が相対的に小さい場合は, 水蒸気密度 のプロフィールは接地薄気層上部で最大値を示すよ うな形状をとることになる（図一1）。このように， 地表面直上の大きな温度勾配の存在は, DSL法が適 用可能な条件の一つを保証する。

\section{VII.むすび}

DSLが形成される段階にいたると蒸発速度の絶 対値は小さい, したがって, 地表面の乾燥が進むと 蒸発速度は零になるというモデルを用いれば，大き な誤差は生じない。そのために乾燥裸地面からの蒸 発過程を理論的に解明する試みはほとんどなされな かったものと思われる.

最近，数値気候モデルに組み込むことを目的とし て, 蒸発速度（潜熱フラックス）をバルク法により 表現する試みが行われている，その際，地表面の湿 度を評価する必要があるが，経験に基づくモデル化 が多数見うけられる (Lee and Pielke, 1992). しか し，理論なきモデル化は，効率の良いアプローチと は思元ない。

裸地面からの蒸発過程, 特に地中からの蒸発が支 配的になる第 2 , 第 3 段階の蒸発過程 (小林・宮川, 1991）についての理論的研究が進められなければな らない. 


\section{引用文 献}

1) Bearman, R.J. and Kirkwood, J.G. (1958) : Statistical mechanics of transport processes. XI. Equations of transport in multicomponent systems, J. Chem. Phys., 28, pp. 136-145

2) Bearman, R.J. (1959) : On the linear phenomenological equations. II. The linear statistical mechanical theory, J. Chem. Phys., 31, pp. 751-755

3) Cary, J.W. (1963): Onsager's relation and the non-isothermal diffusion of water vapor, J. phys. Chem, 67, pp. 126-129

4) Gardner, W.R. and Hillel, D.I. (1962) : The relation of external evaporative conditions to the drying of soils, J. Geophys. Res., 67, pp. 4319-4325

5) de Groot, S.R. and Mazur, P. (1984): Non-equilibrium thermodynamics, Dover, pp. 273

6) 原卦芳信・申 建友・劉 新民・李 勝功 (1992) : 中国内モンゴル東部の砂丘の秋季の微気象特 性, 農業気象, 47, pp. 217-224

7) Ishihara, Y., Shimojima, E. and Harada, H. (1992): Water vapor transfer beneath bare soil where evaporation is influenced by a turbulent surface wind, J. Hydrol., 131, pp. 63-104

$8 ）$ 小林哲夫・松田昭美・神近牧男 (1985): 温度勾 配下での土壤中の水蒸気輸送に関する基礎理論, 九州の農業気象, 21, pp. 21-26

9) Kobayashi, T., Matsuda, A. and Kamichika, M. (1989): A simple method for estimating the rate of evaporation from a dry sand surface, J. Agr. Meteor., 44, pp. 269-274

10）小林哲夫・宮川賢治（1991）：乾燥裸地面加 の日蒸発量推定法, 水文・水資源学会誌, $4, \mathrm{pp}$.
$37-43$

11) Kobayashi, T., Matsuda, A., Kamichika, M. and Yamamura, Y. (1991): Why the thickness of the dry surface layer in sand dune fields exhibits a diurnal variation ?, J. Agr. Meteor., 47, pp. 3-9

12) Kobayashi, T., Nagai, H. and Shibata, S. (投稿中) : Another comment on "Peculiar downward water vapor flux over Gobi desert in the daytime", J. Meteor. Soc. Japan

13) Kondo, J., Saigusa, N. and Sato, T. (1992) : A model and experimental study of evaporation from bare-soil surfaces, J. Appl. Meteor., 31, pp. 304-312

14) Lee, T.J. and Pielke, R.A. (1992): Estimating the soil surface specific humidity, $J$. Appl. Meteor., 31, pp. 480-484

15) Milly, P.C.D. (1982): Moisture and heat transport in hysteretic, inhomogeneous porous media: A matric head-based formulation and a numerical model, Water Resour. Res., 18, pp. 489-498

16) Nakano, M. and Miyazaki, T. (1979): The diffusion and nonequilibrium thermodynamic equations of water vapor in soils under temperature gradients, Soil Sci., 128, 184-188

17) Philip, J.R. and de Vries, D.A. (1957): Moisture movement in porous materials under temperature gradients, Trans. Amer. Geophys. Union, 38, pp. 222-232

18) Truesdell, C. (1962): Mechanical basis of diffusion, J. Chem. Phys., 37, pp. 2336-2344

19) Wang, J. and Mitsuta, Y. (1990): Peculiar downward water vapor flux over Gobi desert in the daytime, J. Meteor. Soc. Japan, 68, pp. 399-401

(1992年 7 月 24 日受付, 1992年12月 3 日受理) 